\title{
O sonho do nixi pae. A arte do MAHKU - Movimento dos Artistas Huni Kuin
}

\author{
Amilton Pelegrino Mattos' \\ Universidade Federal do Acre
}

Resumo: Inspirado no filme $O$ sonho do nixi pae (2014), o artigo percorre a trajetória do MAHKU - Movimento dos Artistas Huni Kuin, traçando paralelos entre o percurso do grupo e a travessia mítica dos huni kuin que atravessaram o jacaré-ponte. $\mathrm{O}$ artigo se dedica a pensar a música e suas transformações em artes visuais e audiovisual desde uma teoria da tradução nativa.

Palavras-chave: Huni Kuin, etnomusicologia, poética, tradução, xamanismo. 


\title{
The dream of the Nixi Pae. The art of MAHKU - Huni Kuin Artists Movement
}

\begin{abstract}
Inspired by the film's Dream of the Nixi pae (2014), the article covers the trajectory of MAHKU - Huni Kuin Artists Movement, making a parallel between the group's route and the mythical crossing of huni kuin who crossed the alligator bridge. The article is dedicated to thinking about music and its transformations in visual and audiovisual arts from the perspective of a theory of native translation.
\end{abstract}

Keywords: Huni Kuin, ethnomusicology, translation, shamanism, poetic.

\section{El sueño del Nixi Pae. El arte de MAHKU - Movimiento de los Artistas Huni Kuin}

Resumen: Inspirado por la película El Sueño del Nixi Pae (2014), el artículo cubre la trayectoria de MAHKU - Movimiento de los Artistas Huni Kuin, estableciendo paralelismos entre la ruta del grupo y la travesía mítica de los Huni Kuin que cruzaron el puente cocodrilo. El artículo está dedicado a pensar en la música y sus transformaciones en artes visuales y audiovisuales desde la perspectiva de una teoría de la traducción nativa. poético.

Palabras clave: Huni Kuin, etnomusicología, traducción, chamanismo, 


\section{O sonho do nixi pae}

O vídeo $O$ sonho do nixi $\mathrm{pae}^{2}$, de 2014, recompõe a constituição e o percurso do MAHKU, movimento dos artistas huni kuin, ao longo dos últimos cinco anos.

Em 2013, na Universidade Federal da Bahia, quando Ibã faz a primeira apresentação do MAHKU, que acabara de se constituir como associação, ele entoou o pakarin (canto) do kapetawã (jacaré grande ou jacaré-ponte). Poucas semanas depois, na exposição Mira, Artes visuais contemporâneas dos povos indígenas, no Centro cultural da UFMG, Belo Horizonte, onde estávamos na companhia dos artistas huni kuin Bane e Keã, Ibã tornou a cantá-lo na cerimônia de abertura.

Ano passado, o MAHKU participou da exposição Histórias mestiças, no Instituto Tomie Ohtake em São Paulo. Dos 15 desenhos realizados para a ocasião, 14 foram huni meka (cantos de ayahuasca) e um dos desenhos o cantomito do kapetawã. $\mathrm{O}$ vídeo mostra nosso encontro com um amigo na exposição, o antropólogo Bruce Albert. Em certo momento, mostrando o desenho do kapetawã e lendo a legenda que pode ser entendida como história dos antigos, Ibã diz a Bruce: shenipabu miyui... shenipabu miyui somos nós...

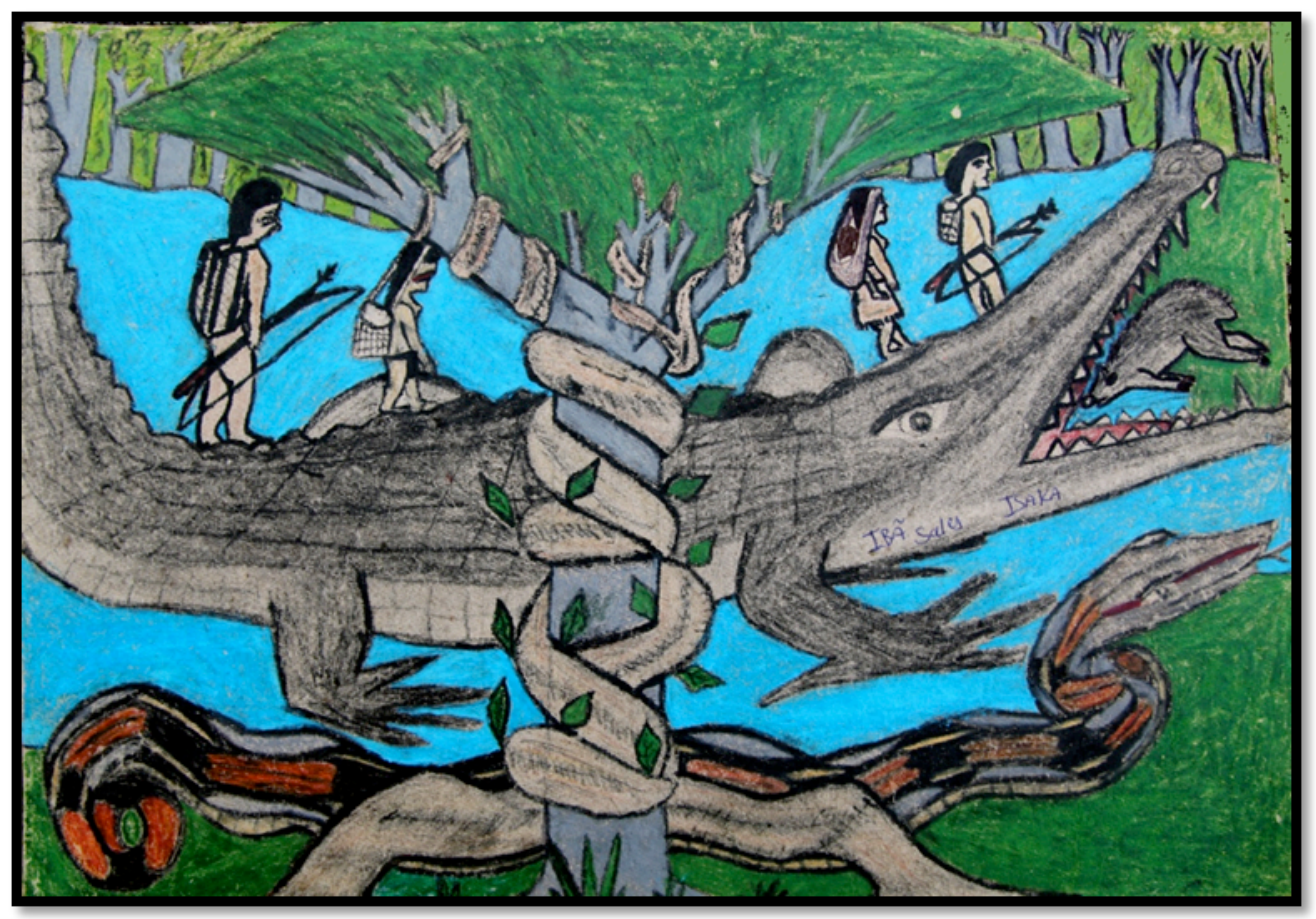

Travessias

Neste artigo trataremos de travessias, de traduções, de antropologias. Ele consiste num apanhado de rizomas que proliferaram no tempo em que editamos

${ }^{2}$ Disponível em https://www.youtube.com/watch?v=8LOL3BMoeRY 
o vídeo $\mathrm{O}$ sonho do nixi pae. Há uma leitura paralela artigo-vídeo: o que escrevemos aqui pode afetar a leitura do vídeo, assim como o que escrevemos é um desdobramento do texto audiovisual.

O projeto Espírito da Floresta resulta do trabalho de pesquisa desenvolvido pelos autores no contexto da Licenciatura da Universidade Federal do Acre, Campus Floresta. O vídeo O sonho do Nixi pae resulta do trabalho do LABI - Laboratório de Imagem e Som da UFAC - Floresta.

Assim como o vídeo, este artigo imagina o MAHKU e sua trajetória como uma travessia similar à travessia mítica dos huni kuin no lombo do kapetawã. Por fim, à nossa maneira, podemos dizer, como já foi dito, escrevemos a dois, mas somos sempre ajudados, aspirados, multiplicados ${ }^{3}$.

\section{História}

Vamos falar do povo huni kuin (kaxinawa). Tudo começa com Tuin Huni Kuin (Romão Sales). Tuin é filho de Tene (Chico Curumin). Eu, Ibã, sou filho de Tuin. Foi com ele que aprendi a cantar: pakarin, huni meka, os cantos que ele cantava no fim da tarde, alegre na sua rede, ensinando seus filhos. Formei professor, aprendi a escrever, adquiri um gravador para gravar meu pai. Aprendi a pesquisar com meu pai. Ele passou a vida aprendendo os cantos, os rituais e outros conhecimentos dos huni kuin mais velhos e mais brabos que chegavam de todas as partes para escapar das correrias, abrigando-se no rio Jordão, no seringal herdado por nossa família de patrões brancos depois de muito trabalho e sob a identidade de caboclos brasileiros, trabalhadores e civilizados. Em 1984, o seringal se torna terra indígena e os huni kuin passam a ser reconhecidos novamente como povo indígena. Tuin agora estava pronto para ensinar tudo o que guardou, tudo o que tinha aprendido. É momento de retomar práticas e rituais que haviam sido perdidos. Os professores das escolas huni kuin empenham-se nesse processo e tem por referência o velho Romão Tuin.

Sou professor indígena desde 1983. Nesse projeto coletivo de pesquisa dos professores, assumi os huni meka, os cantos do nixi pae (bebida ayahuasca), aquelas músicas que mais me impressionavam. Passei anos registrando esses conhecimentos e transcrevendo. Em 2006, publico meu primeiro livro, Nixi pae - O espírito da floresta ${ }^{4}$.

Antes de começar a estudar na licenciatura indígena, em 2009, o txai Amilton chegou na aldeia Chico Curumim. Nesse mesmo ano elaboramos nosso projeto de pesquisa na universidade da floresta. Nossa ideia era continuar pesquisando os cantos huni kuin. Norteava-nos a grande aceitação do livro que tinha atingido diversas terras dos huni kuin e causado impacto sobretudo nas aldeias cuja língua hatxa kuin rareava.

E não era apenas a língua que era assumida pelos jovens, era a língua estranha dos cantos, a linguagem poética que há pouco constrangia. Junto com a vontade de cantar, estimulada também pelo daime dos brancos e a presença dos instrumentos como maracás e violões, os huni kuin também retomaram suas pinturas corporais, voltando a utiliza-las com frequência não apenas nas aldeias, mas a exibi-las publicamente nos municípios próximos às aldeias. 


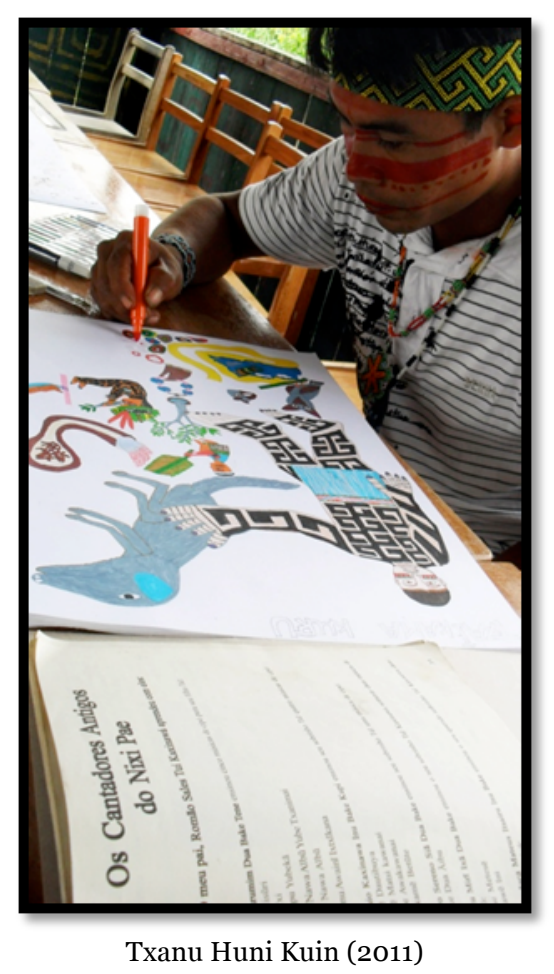

Antes de reencontrar Ibã no Jordão, em 2009, subi o rio Tarauacá com Bane. Chamavam a atenção as atas desenhadas que Bane produzia em reuniões nas aldeias do Jordão.

Desde o início trabalhamos com o audiovisual. Quando nos chegaram os primeiros desenhos de Bane - experiência inicial de 10 desenhos em 2007 passamos a trabalhar com a seguinte composição: desenhos, canto e comentários, vídeo.

Organizamos um Encontro de artistas no Jordão em 2011, coordenado por Bane e Ibã. Durante 10 dias nos dedicamos a desenhar os huni meka (cantos da ayahuasca) de Tuin registrados no livro de Ibã. Ainda em 2011, construímos nosso sítio virtual (www.nixi-pae.blogspot.com.br) e fizemos nossa primeira exposição em Rio Branco. Em 2012 fomos convidados por Bruce Albert e Hervé Chandés para expor na Fundação Cartier para a Arte Contemporânea, na exposição Histoires de voir, com essa série de desenhos produzidos no Encontro. Para essa ocasião realizamos o vídeo $O$ espírito da floresta ${ }^{5}$. Mais importante que nossa projeção para fora da aldeia e do país, essa primeira exposição internacional projetou-nos para dentro. Reunimo-nos na aldeia em agosto de 2012 e criamos o MAHKU, Movimento dos Artistas Huni Kuin, coletivo de artistas e associação.

\section{Cantos-desenhos}

Nosso trabalho tem origem, portanto, na convergência de canto, desenho e vídeo. Os desenhos traduziam a música numa visualidade própria a esse universo musical e o vídeo fornecia recursos para evidenciar essa relação. $O$ vídeo possibilitava fazer convergir imagem e canto, coloca-los paralelos ou justapostos. 
A visualidade, construída com os recursos do paralelismo e justaposição (CESARINO, 2006), é característica principal da dimensão verbal dos cantos huni meka.

Os comentários aos cantos (pôr no sentido, ver adiante) feitos por Ibã no vídeo, simulam essa articulação na medida em que não explicam, e sim criam um texto paralelo à imagem-música, tal qual o desenho propõe em relação à música-texto.

Se os textos dos cantos são marcados por paralelismo e justaposição, essas características não vão faltar aos desenhos e pinturas. $\mathrm{O}$ mesmo vale para a linguagem formulada por Ibã para pôr no sentido, como fica claro na sua fórmula que explora a parataxe para nos aproximar dessa linguagem e apresentar a convergência canto/desenho: nai manpu yubekã, céu pássaro jiboia.
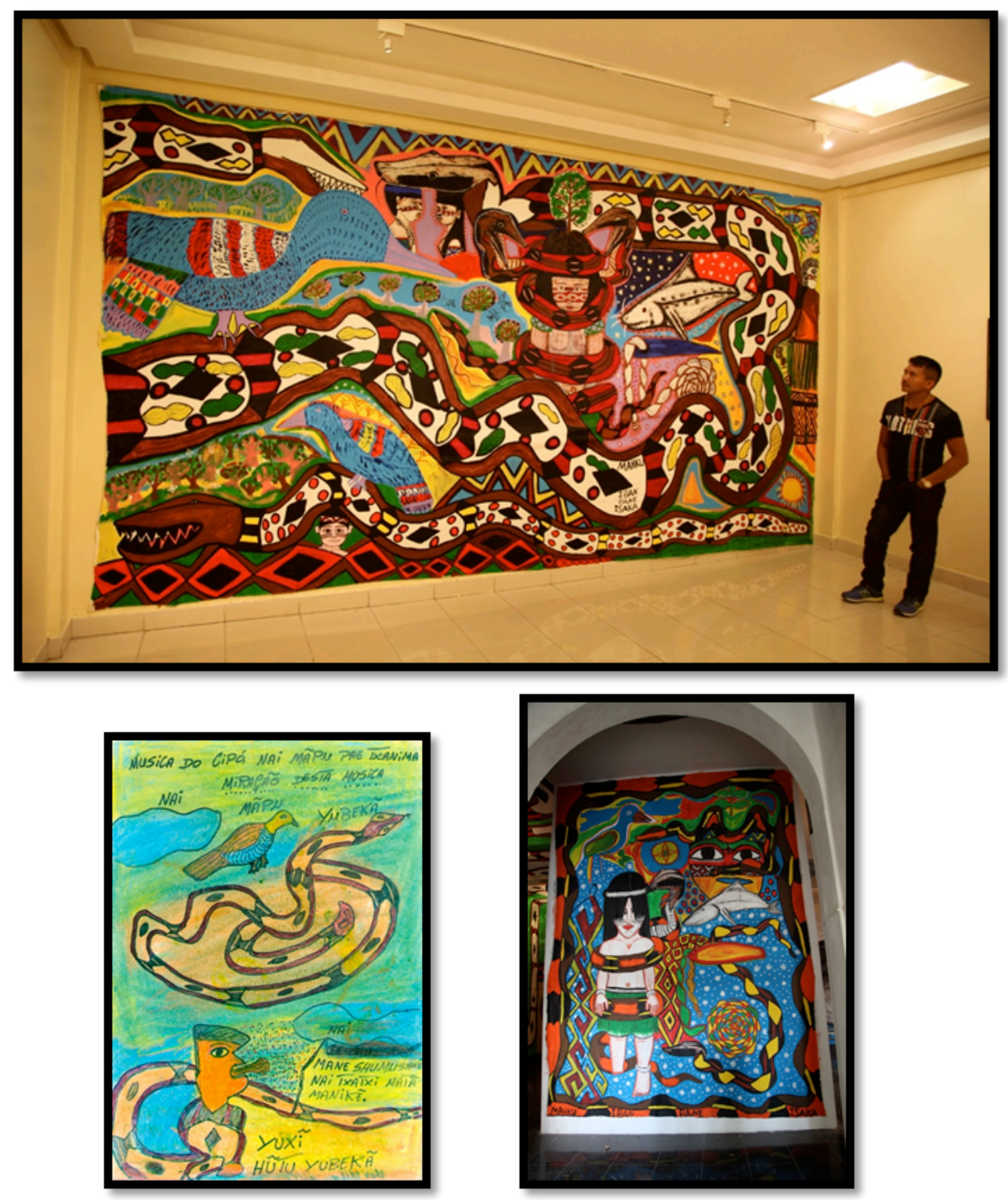

Temos aqui uma série de imagens de um mesmo canto. O canto nai manpu yubekã aparece na primeira, desenho de Bane de 2007. Imagem 2, painel de $5 \times 3$ metros pintado pelo MAHKU (Bane, Isaka e Ibã) em 2014, na exposição Made by... Feito por brasileiros, em São Paulo. Na terceira, outra pintura de 3x6 metros pintada pelo MAHKU (Bane, Isaka e Ibã) em 2014, na 
exposição Nixi paewen namate - O sonho do nixi pae, realizada pelo MAHKU no SESC de Rio Branco.

Nota-se que os trabalhos de Bane não têm a linha do horizonte que organiza a lógica sintagmática letrada da tradição ocidental. Está praticamente ausente dos desenhos, como dos cantos, portanto, uma dinâmica de narração, visto que os elementos da narratividade: espaço, tempo, personagens, são organizados, na linguagem visual, pela linha do horizonte.

Os desenhos propõem outras conexões. O que se tem é a contiguidade, a superposição, características próprias dessas artes verbais como de outras tradições orais.

Nessa primeira série, as figuras parecem emergir do papel ao som da música, evidenciando o jogo de planos que simula a justaposição ou a sucessão de imagens da música que se dá por sobreposição. Temos dois desenhos de Bane: Dua meke newane (2010) e Yube nawa ainbu (2011).

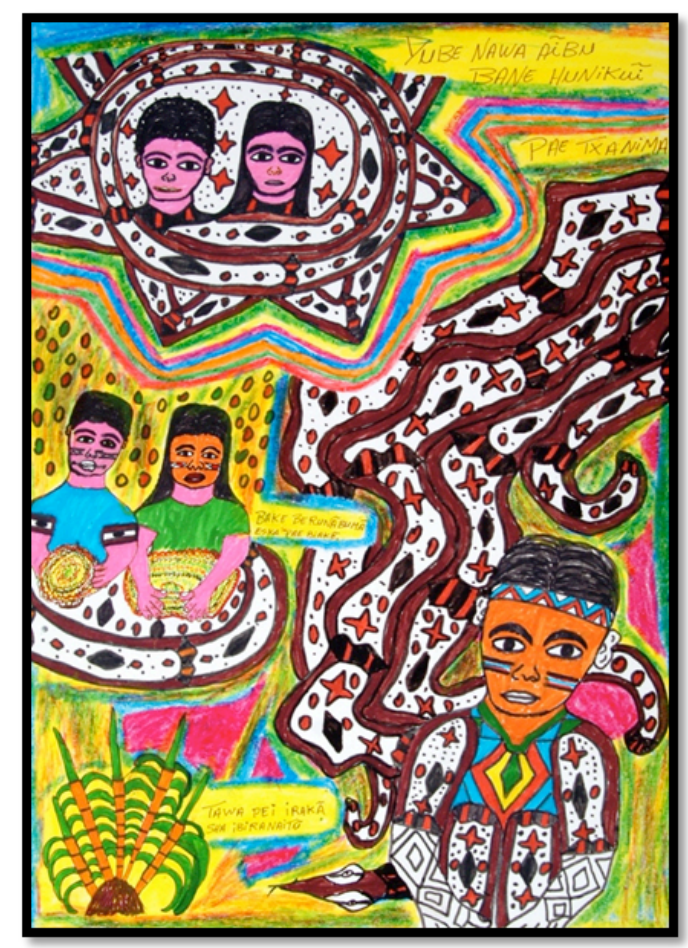

Dua meke newane (2010)

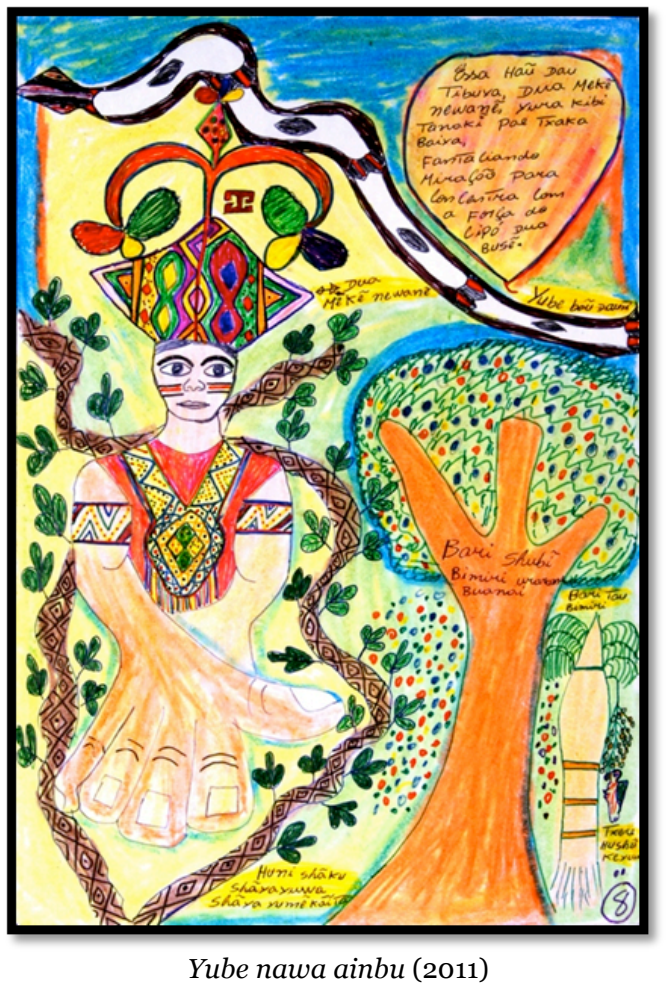

Yube nawa ainbu (2011)

Esse jogo de planos, quando acompanhado da música, dá a perceber uma dinâmica, em que as imagens avançam, emergem para o primeiro plano de acordo com os versos.

Desde o início, a ideia de transformar os cantos em desenho animado vinha à tona em nossas conversas. Porém, sempre estacávamos diante da aridez narrativa dos cantos ou éramos reconduzidos ao mito e nos afastávamos da música. Nesses cantos não ocorre narração, os versos são tratados como imagens que vão se sucedendo e justapondo, compondo blocos de imagens mais do que uma única imagem. Os blocos de imagens são marcados nos desenhos por recursos diversos. No desenho Dua meke newane (2010), o cipó é imagem cantada em alguns versos e também serve para destacar o yuxibu (espírito) que 
é composto com a sobreposição de fragmentos da imagem (a mão grande, o cocar, gestos ou movimentos).

\section{Miração}

Mesmo se tratando de cantos, a percepção visual é fundamental tanto nas palavras que são cantadas como no ritual do nixi pae que gira em torno das visões. As visões ou mirações não são visões cotidianas, elas consistem num código sensorial outro ${ }^{6}$.

Bane refere-se à sua iniciativa de desenhar os cantos nesses termos: eu vi que o que estava faltando era ver a miração (O sonho do nixi pae, 2014). Marca da visualidade está na definição dos três tipos de cantos huni meka: entre os cantos de chamar a força e diminuir a força estão os dautibuya, cantos de miração, que recobrem a maior parte do ritual de nixi pae.

Um exemplo: um dos cantos mais importantes ensinado por Tuin, hawe dautibuya, refere-se àquele que vem adornado, enfeitado, transformado, potente. Outros exemplos: txai puke (Bane, 2007), dua meke (Bane, 2010), hawe dautibuya e dua meke (Mana, 2014). Trata-se de cantos de dar a ver, chamar ou potencializar a visão. Os desenhos são descritivos, mas não se trata de descrever o que se vê, e sim de alterar a visão para dar a ver algo que não pode ainda ser visto.

Portanto, não se trata da visão cotidiana, mas de uma visão transformada, aprimorada, talvez uma hipervisão, que também precisa ser traduzida ou transcriada, tal como se dá com a poesia dos cantos tornada desenhos no papel e no giz, nas tintas e na tela. Em outro momento, Ibã ( $O$ espírito da floresta, $2012^{7}$ ) comenta esse trabalho artístico:

\footnotetext{
Então foi isso que eu sonhei dentro da miração, dentro do meu sentido, que dá pra fazer isso e mostrar, para aquele que não chega, aquele que não conhece ainda bebida ayahuasca, dá pra entender; tem gente que ficava com medo, por isso que eu fiz desenho; na hora que você convidava pra realidade, pra mostrar o trabalho, tem gente: ah não, tenho medo, eu vejo cobra, talvez eu veja alguma coisa do futuro; dá pra entender melhor aquele que nunca tenha conhecido, seja huni kuin ou não: ah, isso que está falando na música...
}

Há uma travessia a ser feita. As tradições poéticas ocidentais ignoram até hoje as artes verbais dos povos ameríndios. Um amadurecimento recente na forma de ver esses povos e seu pensamento cria condições para uma tradução dessa poética. De Lévi-Strauss ao perspectivismo ameríndio $^{8}$, há um trabalho de tradução primeiro, que abre caminhos para propostas. Assim que a etnologia passa a aceitar essas outras antropologias implicadas no pensamento ameríndio, a tradução perde seu caráter unidirecional. O tradutor ocidental ao traduzir o texto indígena para sua poética pode suprimir esse trabalho de tradução primeiro. Portanto, esse movimento não pode restringir-se à inclusão de uma literatura indígena.

\footnotetext{
${ }^{6}$ Cf. Barbara Keifenheim, no artigo "Nixi pae como participação sensível no princípio de transformação da criação primordial entre os índios kaxinawa no leste do Peru”, In: Beatriz Caiuby Labate e Wladimyr Sena Araújo (orgs.). $O$ Uso Ritual da Ayahuasca. Campinas, Mercado de Letras, São Paulo, Fapesp, 2002.

7 https://www.youtube.com/watch?v=zRlbRpoiocQ

${ }^{8}$ Eduardo Viveiros de Castro. A inconstância da alma selvagem e outros ensaios de antropologia, São Paulo, Cosac \& Naify, 2002.
} 
Traduzir é transformar, criar. Os huni kuin, numa antropologia reversa ${ }^{9}$, estão traduzindo à sua maneira, para nós, não apenas sua poesia e sua poética, mas também a escrita, as artes visuais e mesmo a escola, a pesquisa, a universidade.

A tradução que nos propomos liberar aqui não é apenas uma tradução dos cantos huni kuin nos termos da tradução servil ${ }^{10}$ dos brancos. Os huni kuin, pela perspectiva ou devir-animal da jiboia, traduzem, através de seus cantos e desenhos, outras possibilidades de mundo. Ao traduzir, reinventando sua realidade a partir da realidade não indígena, traduzem-se a si próprios, intensificando-se como verdadeiros, como huni kuin.

Essa música vocal do huni meka opera com diversos recursos que compõem intensidades, campos de força: repetição de palavras e de sons, vocalizações, aceleração e desaceleração, movimento e repouso, quebra do som e extensão etc.

Associados a esses efeitos sonoros, as imagens descritas nas palavras dos cantos vão compondo imagens que se relacionam com a miração. Essa noção de miração será aqui combinada com o tornar visível de Paul Klee. Referimo-nos a um material visual que deve capturar forças não-visíveis (Deleuze e Guattari, 1997: 158).

Como dizem Deleuze e Guattari, não estamos mais tratando de uma relação matéria-forma. Ela se apresenta aqui como uma relação direta materialforças; captar as forças do cosmos numa obra; para tal obra é preciso meios muito simples, muito puros, quase infantis, mas é preciso também as forças de um povo, um povo por vir ${ }^{11}$.

Além de conduzir a uma perceptividade do visual própria do jogo de imagens dessa poesia, bem como dos efeitos sonoros empregados nesses cantos para modular intensidades, as imagens das pinturas constituem uma linguagem própria de um processo de transcriação interespecífica: trata-se de traduzir o que foi apreendido com exeika, a jiboia. A fórmula nai manpu yubekã, configura com sua parataxe, sua contiguidade e sobreposição, uma linguagem poética própria.

\section{Pôr no sentido: traduzindo mundos}

Sintetizamos essa poética dos huni meka na fórmula nai manpu yubekã: nai é céu, manpu é o pássaro, yube é a jibóia; ela também sintetiza aquilo que chamamos colocar no sentido.

Ibã criou a expressão pôr no sentido para se referir ao que estávamos fazendo: os seus comentários, em vídeo, acompanhados do desenho e da música. Entendemos que pôr no sentido, essa expressão um tanto enigmática que ele criou com seu português crioulo huni kuin, define um processo de leitura que aprendeu com Romão, que o ensinava que as músicas cifram conhecimentos numa linguagem poética que constitui quase um idioma outro.

\footnotetext{
9 Antropologia reversa, conforme sugeria Bruce Albert (1995) a respeito da política cosmológica acionada na dimensão xamânica dos relatos de Davi Kopenawa (1990) tratando da invasão e dos massacres: Bruce Albert. O ouro canibal e a queda do céu. UnB, 1995. Por fim, esse discurso tem interesse por seu efeito de desconstrução cultural da fronteira: como crítica xamânica do fetichismo do ouro, é claro, mas, o que é ainda mais interessante, como reverse anthropology (Wagner 1981: 31) do ecologismo pós-moderno (idem: 5)

${ }^{10}$ Tradução servil é expressão elaborada por Haroldo de Campos (1981: 179-80).

${ }_{11}$ "Não há mais matéria que encontraria na forma seu princípio de inteligibilidade correspondente. Trata-se agora de elaborar um material encarregado de captar forças de uma outra ordem: o material visual deve capturar forças não visíveis. Tornar visível, dizia Klee, e não trazer ou reproduzir o visível” (DELEUZE e GUATTARI, 1997: 158).
} 
Sobre essa prática de pôr no sentido, um registro feito por Ibã com Tuin há cerca de dez anos, possibilita algumas considerações sobre a natureza dessa poesia e a aprendizagem de Tuin. A certa altura ele faz uma pausa no canto pakarin para decifrar alguns versos, pôr no sentido como dizemos. Ibã então interrompe, pedindo que ele continue o canto, pois queria grava-lo. $\mathrm{O}$ velho se nega e diz que precisava decifrar o sentido para que o filho entendesse o que estava sendo cantado. Ouvindo hoje esse episódio, acreditamos que Tuin estava aqui nos ensinando a respeito da prática de pesquisa que aprendeu ao longo de sua vida ouvindo os antigos.

\section{Audiovisual}

O mesmo com o audiovisual, não se trata de escrever a respeito desse trabalho, trata-se de criar, assim como o desenho faz com a música, criar a partir dela. Com o audiovisual pudemos convergir, articular, dispor no tempo e na percepção os cantos e a criação visual, os desenhos. Fizemos isso com outra linguagem.

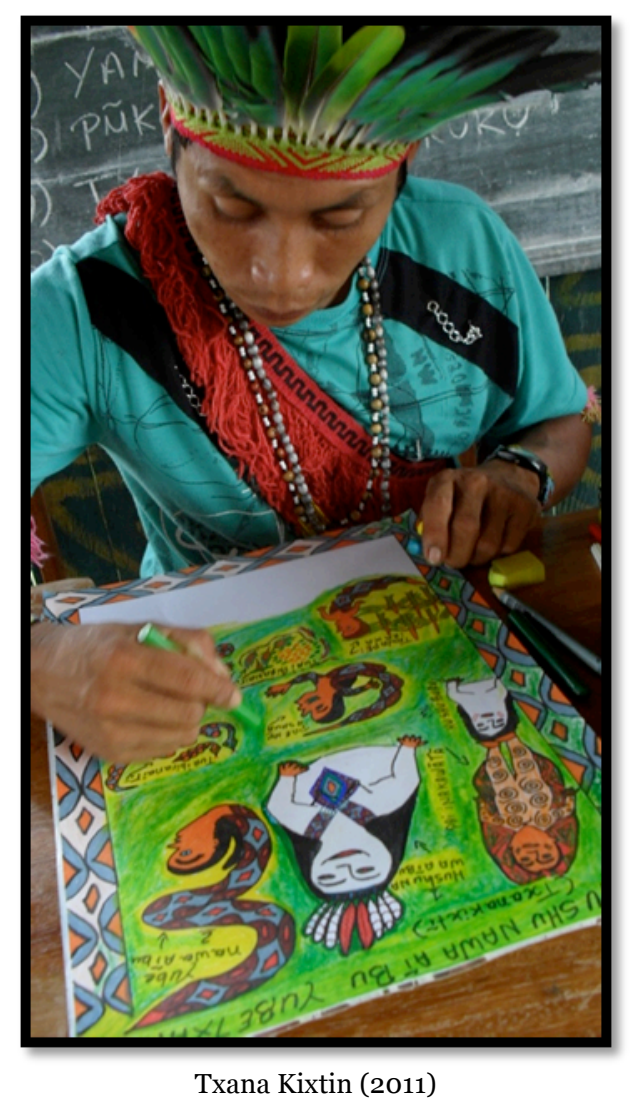

Interessa-nos a linguagem do vídeo como possibilidade de criação de realidade. $\mathrm{O}$ vídeo possibilitou fazermos da criação um percurso, ele tornou mais claro que nossa criação era um percurso, que era nesse rumo da travessia que nos levava nosso trabalho. 
A câmera opera como catalizador. Como o que se diz a respeito da física quântica, que a realidade pode ser afetada ou produzida pelo pesquisador.

Percebo que a interação entre o trabalho e o registro, isto é, os huni kuin se criando, produziu um desdobramento que nos abriu mais possibilidades de nos recriarmos, de compor um corpo coletivo que nos possibilita viver a experiência artística como alternativa para escapar aos modos de existência que se impõem pela economia local, tais como a funcionarização, o etnoturismo ou o assistencialismo de estado.

O trabalho do movimento dos artistas huni kuin tem como origem a pesquisa de cantos, rituais, língua e outros conhecimentos, feita por Romão Sales ao longo de sua vida. Dessa maneira, entendemos todo esse percurso como capacidade de desenharmos a nós mesmos, de nos criarmos como huni kuin, como povo verdadeiro, como gente de verdade. Os antigos nos ensinam que só somos verdadeiros, inteiros, protegidos se estivermos pintados. O poder do keneya é definidor na elaboração de si. Estar pintado ou trajar roupas com kene ou dormir na rede de kene é atributo para estar completo, forte, saudável ${ }^{12}$.

\section{Etnografias}

pulsão dionisíaca, [que] põe a cristalografia em reebulição de lava Haroldo de Campos

O universo dos desenhos indígenas impressiona. Mas perceba-se que aqui não estamos falando apenas de desenhos, falamos de uma etnografia, uma etnografia visual que já é a tradução de uma etnografia feita na música, mas sobretudo pela música. Essa música não fala de outros mundos, não se refere apenas a esses outros mundos, essa música nos comunica desde o início que esse mundo em que vamos entrar não é um mundo em que podemos referir às coisas, como se as coisas fossem fixas e os significados, sentidos, ou nomes variassem. É aí que a música faz, que a música é, e não quer dizer ou representa. Essa etnografia feita pela música como descrição de outros mundos (outras culturas): mundo da jiboia, mundo do vegetal, do cipó, não pode ser feita sem problematizar de saída a relação do pensamento ocidental com a linguagem e com o mundo concebido como realidade. $\mathrm{O}$ mito deixa os rastros disso que a música faz. Ele é palavra, narrativa. Já essa música, não diz respeito a alguma coisa, ela cria intensidades. Entrar, permanecer e sair da força: os três huni meka. quando falamos que a música cria um campo de intensidades, isso fica claro em expressões como força (essa música serve para chamar a força ou esse canto é de diminuir a força).

Ao colocar no sentido o canto Txai puke dua, Ibã diz que esse canto serve para você ver seu trabalho e fala a respeito do xinã , que chama de pensamento, e dá o exemplo no vídeo Puke dua ainbu ${ }^{13}$ (2012):

Xinã besua ketã: xinã é nosso segredo de pensar, dentro, o que você pensando, construiu uma casa, por exemplo, esse é o seu segredo do seu pensamento, que você fez; besua, você está olhando, virando o pescoço, o olhar no rumo que você quer.

\footnotetext{
12 O mesmo se dá com a expressão dami (O sonho do nixi pae, 2014), que se refere a desenho e a transformação. Quando se está no ritual, em conexão com o nixi pae, a gente encanta da mesma maneira que a jiboia; estamos no corpo e fora dele, transformados; somos damini e damiwa, gerando e sendo gerado; quando estamos desenhando/filmando, desenhamos e somos desenhados.

13 https://www.youtube.com/watch?v=pIogob2qGDI
} 
A ideia de desenhar também não é alheia a essa natureza tradutória dos cantos que de um lado é tradução ou etnografia de outros mundos, e de outro é uma tradução que ao traduzir o outro, traduz o próprio huni kuin (WAGNER, 2010: 36-7).

A floresta é viva, é sensível. Os animais, as plantas são seres não apenas sencientes, são dotados de conhecimentos e perspectivas inauditas que precisam ser "traduzidos". Os huni kuin foram construindo nos mitos uma visão do mundo que traduz para não especialistas, huni kuin ou não, alguns conhecimentos que são próprios de conhecedores como os txanas $^{14}$, melhor referido em português como cantor. Os mitos traduzem práticas que são atualizadas em outras linguagens como a música, os cantos.

Portanto, há uma outra tradução dos cantos e do fenômeno ayahuasca, bem como de seu ritual, entre os próprios huni kuin. O que se diz é que se trata de um mito a respeito da origem do nixi pae. Com essa expressão, sob o nome de nixi pae está a bebida, evidentemente, mas também outros segredos da família de Yube Xanu.

\section{Mito e canto}

Se pensarmos o mito como tradução dos cantos, da percepção colocada em experimentação no ritual nixi pae, das relações entre humanos e não-humanos que são descritas nessa poética dos cantos, também sua dinâmica narrativa começa a ser afetada. Não se trata do que diz o mito, mas do como diz, quais os recursos, as velocidades, os cortes, os detalhes, o que ele esconde ou não dá a ver, do que é rápido demais para ser percebido. Mesmo que seja uma narrativa, o mito traz ecos da alteração da percepção que define a prática do nixi pae.

$\mathrm{O}$ mito de referência, como tantos outros, versa sobre o modo de ver de humanos e não-humanos, trata do que acontece quando se vê uma outra humanidade, sobretudo quando nos vemos huni kuin nos termos do outro.

$\mathrm{O}$ mito não traduz um mundo objetivo, traduz um mundo afetado, mas sobretudo sua transformação. O mito versa sobre o processo de transformação. Ele não apresenta um processo de transformação, o seu tema é a transformação, o transformar-se ${ }^{15}$. A princípio transformação na maneira de ver, de perceber, yube inu se transforma em jiboia. Depois no próprio corpo, ele se transforma em cipó, destinado a ser transformado e bebido.

Essa etnografia do mundo da jiboia, da linguagem da jiboia é feita nos cantos e em sua prática. Os desenhos dos cantos, no entanto, não "descrevem objetivamente o que se vê", como poderia se esperar de uma etnografia. São uma etnografia voltada para a potência de criação da linguagem.

O desenho também é tradução, mas essa tradução não transforma apenas um sentido que estaria por trás da letra. Ele simula a linguagem que o canto manifesta, cria como campo intensivo ou plano de imanência. Sobretudo, esse processo de tradução converte aquilo ou aquele que está diante da tela, o artista, o huni kuin. O keneya é ao mesmo tempo pintor e pintado.

14 Categoria que não deve ser confundida com o genérico pajé pois não é a única categoria de especialistas desses saberes das plantas, dos animais, das curas etc; há outros especialistas desses conhecimentos. Barbara Keifenheim (2002) comenta o xamanismo huni kuin.

15 Aqui se cruzam linhas interpõem xamanismo e caça, visto que a caça é prática privilegiada para uso e transformação dos sentidos. A caça, tal como o xamanismo, consiste num espaço privilegiado para experiências de sentido no limite. Nos mitos os encantados sempre manifestam prodígio na caça, quase sempre por suas qualidades perceptivas. 
Por isso a preocupação de pôr no sentido, de traduzir à maneira dos huni kuin, em que importa entender a natureza da linguagem do outro. No caso, a linguagem com que a jiboia teria traduzido ela mesma, ainda, por sua vez, uma outra língua, a língua do vegetal.

A natureza dessas músicas é traduzida no mito. Elas resultam de uma incursão, também um casamento e uma transformação, de um huni kuin ao mundo da jiboia, do huni kuin jiboia. Essas músicas, assim como a bebida ayahuasca, são um conhecimento secreto do mundo da jiboia.

Não há tradução possível aqui sem essa etnografia, sem lançar-se na experimentação de linguagens, de tradução de mundos. Não é possível tampouco tratar do que estamos fazendo se não considerarmos a perspectiva da jiboia, se não considerarmos essa antropologia interespecífica com que os huni kuin se fazem verdadeiros ${ }^{16}$.

Como procuramos traduzir aqui, não se trata de uma relação matériaforma, como dizem Deleuze e Guattari, e sim uma relação direta materialforças. É assim que o material visual deve capturar forças não-visíveis. As matérias de expressão dão lugar a um material de captura e, a partir daí, as forças a serem capturadas não são mais as da terra, que constitui ainda uma grande forma expressiva, elas são agora as forças de um cosmo energético, informal e imaterial ${ }^{17}$.

\section{Tradução}

São várias dimensões de tradução implicadas nesses cantos. De um lado, trata-se de traduzir de uma língua para outra, de uma geração para outra (língua mais antiga), de uma linguagem poética para uma linguagem objetiva, do som/palavra para a imagem e até de uma cultura para outra. De outro, ainda, trata-se também de traduzir de uma cultura para outra, mas numa tradução interespecífica, uma tradução de mundos de animais e vegetais, que implica o perspectivismo huni kuin e a equivocação controlada proposta por Eduardo Viveiros de Castro ${ }^{18}$.

Nós articulamos canto, desenho e vídeo para dar conta de recriar essa arte verbal, sonora e visual. No entanto, entendemos que nossa tradução não se restringe a dar a entender o sentido das palavras nas canções. Nossa tarefa tradutória é definida por Ibã como pedagogia huni kuin e alinha-se com aquilo que Deleuze e Guatari podem chamar de artesão cósmico.

Nosso interesse está nos processos de criação, nas performances, mais do que nos desenhos, quadros enquanto objetos ou mesmo linguagem. Isso ficou claro desde o primeiro encontro de artistas-desenhistas, ninho do MAHKU. Os artistas criaram desenhos recriando a língua de yube. Ao mesmo tempo, também estavam criando a si próprios como artistas, estavam criando o Movimento dos Artistas Huni Kuin, estavam criando outros tantos artistas que vem compor o MAHKU. Trata-se de uma tradução criadora. Se os huni kuin, povo verdadeiro, são verdadeiros na medida em que são keneya, isto é, pintados e pintores ao mesmo tempo, trata-se de criar o povo verdadeiro, huni kuin.

\footnotetext{
${ }^{16}$ No ato de inventar outra cultura, o antropólogo inventa a sua própria e acaba por reinventar a própria noção de cultura (WAGNER, 2010: 31).

17 Ver ainda ROMANDINI, 2012.

18 "Indigenous perspectivism is a theory of the equivocation, that is, of the referential alterity between homonymic concepts" (VIVEIROS DE CASTRO, 2004: 5).
} 
Não se trata de reinventar-se, porém, a partir do nada ou de categorias artificiais do mundo não-indígena. A categoria artista, com que os jovens huni kuin que compõem o grupo se identificam ou fazem devir, não foi concebida desvinculada do trabalho de pesquisa. Mas atentemos para a especificidade dessa pesquisa que consiste numa atividade a que Ibã tem dedicado toda sua vida. Principalmente se entendemos que o conhecimento huni kuin é uma qualidade para a qual a pessoa é preparada desde quando é concebida. Desde o nascimento até os rituais de iniciação, prepara-se a pessoa huni kuin para ter boa memória e aprender os cantos, por exemplo. E essa pesquisa como obra de uma vida, por sua vez, consiste não apenas na apropriação e transmissão daquilo que herdou de seu pai, e sim principalmente em recriar essa atividade de pesquisa, seleção, comparação, armazenamentos, partilha, zelo entre tantas outras, articulada a um processo de recriação mítico ou poético contínuo do povo verdadeiro.

Não tentamos, no entanto, reconduzir para um princípio de identidade, e sim colocar em relação essa pesquisa com a pesquisa acadêmica, quando essa pesquisa se inventa para proporcionar uma antropologia reversa. A interface desse processo é a interação com o universo não-indígena: o mundo da arte, a universidade e a pesquisa, mesmo a prática escolar.

Quando Ibã, em apresentação no CESTA (USP) ${ }^{19}$ ao ser questionado se aprendera a pesquisar na universidade (UFAC), ele responde, com todo respeito: a universidade tem que aprender comigo. Pode parecer pretensão, mas talvez precisemos entender o que ele quer dizer com isso, pois de fato a maneira de pesquisar que ele aprendeu com seu pai só poderia ser aprendida entre os huni kuin, é algo que seu pai aprendeu a fazer com seu povo a partir de sua própria inteligência, percepção e tudo o mais que o qualificava para realizar esse trabalho. A partir daí esse conhecimento é redefinido na relação com o outro, com a universidade e a pesquisa acadêmica. É algo que a universidade, à medida que se proponha a trabalhar pesquisa em parceria com indígenas, precisa compreender. Essa é nossa experiência.

Mas não é só isso, esse trabalho-obra-pesquisa caracteriza-se por um princípio outside (ROMANDINI, 2012), por ver a universidade de fora, de fora do universo autocentrado ocidental.

Essa possibilidade de transformação da universidade aberta por meio da pesquisa que realizamos, que aprendemos com Tuin e com os huni kuin e que se desdobrou em projetos como Espírito da floresta e MAHKU, assim como nossa proposta de transformação da escola (indígena e não-indígena) através daquilo que chamamos de pedagogia huni kuin, pode ser entendido nos termos de uma antropologia reversa ${ }^{20}$.

Tal como proposto por Viveiros de Castro (2004), a antropologia que coloca em jogo o perspectivismo ameríndio implica um processo de tradução como equivocação controlada, pois enquanto o tradutor ocidental permanece nos limites da ontologia naturalista, a teoria da tradução huni kuin, diferentemente, opera com a transformação de mundos e invenção de culturas (WAGNER, 2010). Esse processo se dá a partir da ação e de conhecimentos apreendidos com atores como exeika, a jiboia-sogro, e kapetawã, o jacaréponte.

\footnotetext{
19 O trecho narrado encontra-se no vídeo O sonho do nixi pae, para ver a apresentação no CESTA (USP) na íntegra o endereço é: http://vimeo.com/62086730

${ }^{20}$ Ver nota 8.
} 
$\mathrm{O}$ interesse do huni kuin pelo fora ${ }^{21}$ ganha um sentido diverso. O que caracteriza o huni kuin é esse movimento para o fora, esse buscar-se no fora, essa abertura ao cosmos, esse tornar visível, um agenciamento (pensamentoestética-ética) que nos orienta em tempos de formular uma filosofia do outside (ROMANDINI, 2012). "Meu pai dizia que o jacaré grande vem de antes da estrela, exeika também” diz Ibã no filme.

Forças cósmicas. Não se trata de ficar no âmbito da história, da terra, e sim de abrir para o cosmos. Não se trata, como já dissemos, de sermos incluídos na arte ocidental, e sim da arte ocidental ser confrontada com essa abertura para o cosmos, para as forças cósmicas.

\section{Povo huni kuin ${ }^{22}$}

Huni kuin pode ser traduzido como gente verdadeira, humano verdadeiro ou povo verdadeiro, ou ainda os verdadeiros homens conforme Tastevin (2009: 144).

A exemplo de outros povos, os huni kuin retomam sua autodesignação com mais intensidade na última década. Como tantos outros povos indígenas do continente, os huni kuin compõem sua autodesignação com o intensificador verdadeiro (kuin).

O termo kuin vem sendo problematizado há tempos. Sua tradução como verdadeiro gera equívocos ${ }^{23}$. Interessa-nos muito, porém, a caracterização do adjetivo como um intensificador.

Tratando do perspectivismo das cosmologias ameríndias, Eduardo Viveiros de Castro considera a noção de humanidade no pensamento indígena distinguindo que as autodesignações coletivas de tipo 'gente' significam 'pessoas' e não 'membros da espécie humana'; e elas são pronomes pessoais, registrando o ponto de vista do sujeito que está falando, e não nomes próprios (2002: 372). Segundo o autor, essa identificação entre gente e o nome do povo indígena teria sido produzida na interação com o etnógrafo ${ }^{24}$.

E mais, segundo o autor, essa definição da autodesignação está diretamente ligada ao fato de a maioria dos etnônimos ameríndios não serem autodesignações, mas nomes (frequentemente pejorativos) conferidos por outros povos: a objetificação etnonímica incide primordialmente sobre os outros, não sobre quem está em posição de sujeito (2002: 372).

Os huni kuin entraram para a história como kaxinawa ${ }^{25}$, nome que Tastevin traduz por homens vampiros. Era esse o nome utilizado desde os tempos do contato. Foi com esse nome que as terras indígenas foram registradas. Era como todos se referiam aos huni kuin, inclusive o nome como o estado, que nunca aceitou seus nomes próprios, aceitava registra-los.

\footnotetext{
${ }^{21}$ Ver KEIFENHEIM, 2002.

${ }^{22}$ Sobre a noção de povo que vimos tratando, ver Ritornelo, de Deleuze e Guattari, Mil platôs, 1997: 152 e seguintes.

23 Barbara Keifenheim (2002) escreve sobre o sintagma huni kuin em lugares diversos; ela critica a tradução de kuin pelo termo "verdadeiro", apontando para o sentido de núcleo endógeno, numa interpretação que esbarra com a de Viveiros de Castro a seguir.

24 “A primeira coisa a considerar é que as palavras indígenas que se costumam traduzir por 'ser humano', e que entram na composição das tais autodesignações etnocêntricas, não denotam a humanidade como espécie natural, mas a condição social de pessoa, e, sobretudo modificados por intensificadores do tipo 'de verdade', 'realmente', 'genuínos', funcionam, pragmática quando não sintaticamente, menos como substantivos que como pronomes. Elas indicam a posição de sujeito; são um marcador enunciativo, não um nome. Longe de manifestarem um afunilamento semântico do nome comum ao próprio (tomando 'gente' para nome da tribo), essas palavras fazem o oposto, indo do substantivo ao perspectivo (usando 'gente' como a expressão pronominal 'a gente')” (VIVEIROS DE CASTRO, 2002: 371).

${ }_{25}$ Tastevin, 2009:144.
} 
Sobre a produção de nomes nas primeiras décadas do século XX, período de contato intensivo dos huni kuin com a sociedade seringalista, Tastevin ${ }^{26}$ (2009: 113-4) chama a atenção para um ponto a ser considerado na adoção e disseminação de nomes. Ele narra o caso de povos adotando o nome de outros grupos que já eram conhecidos como mansos, que já tinham sido amansados. $\mathrm{O}$ objetivo era proteger-se de uma possível confusão com povos desconhecidos e brabos.

Assim, para os kaxinawa era cômodo manter-se sob um nome conhecido, que lhes dava segurança, ainda que esse nome fosse mais um eles que um nós.

Retomando Viveiros de Castro e os pronomes cosmológicos, depois de falar do nós e do eles, trata-se agora da segunda pessoa. Segundo o autor, responder a um tu dito por um não-humano equivale (equivoca) a colocar-se numa perigosa posição/condição de não-humano, pois apenas os xamãs seriam capazes de transitar pelas perspectivas sem terem ameaçada sua humanidade.

Entre os huni kuin, constata-se cada vez menos uma distinção clara entre xamãs, txanas e outros (KEIFENHEIM, 2002). O uso da ayahuasca associa-se cada vez mais ao tornar-se huni kuin. Mais que um sistema de cura restrito, a prática pode ser entendida como uma estética da percepção ${ }^{27}$ que engaja os participantes na metamorfose contínua das formas e dimensões - o que chamamos aqui de forças cósmicas - e que define a importância dos processos de transformação visual no seu pensamento ${ }^{28}$.

Propomos aqui que a arte, conforme apropriada e colocada como mediador na relação com o mundo não-indígena, opera como extensão e tradução dessa prática xamânica: as etnografias poéticas e visuais. Os processos de tradução. As práticas sinestésicas. O tornar visível as forças não-visíveis. A experimentação do complexo perceptivo do corpo como prática central de um regime de pensamento. $\mathrm{O}$ engajamento na transformação ou movimento das forças cósmicas.

Essa conclusão do perspectivismo ameríndio, apontando para a possibilidade de assumir outras perspectivas sem perder (ou perdendo, ou compondo, ou devindo etc) sua humanidade nos remete a um huni meka. Trata-se de um kayatibu, um canto que se canta para diminuir a força, encerrar o ritual e, portanto, certificar-se do retorno de todos para suas próprias perspectivas, isto é, para sua condição de humanos, ou de huni kuin, humano de verdade (ou hiper humano) na medida em que o ritual pode ser entendido como uma atividade de intensificação de humanidade.

\footnotetext{
${ }^{26}$ Por que se diziam Katukina? Supõe-se que para evitar a perseguição dos brancos. Quando estes apareceram na região, eles se apresentaram acompanhados de índios Katukina e Kanamarí, que eram amigos dos civilizados havia tempo. Todos os índios do grupo pano tinham então uma reputação, talvez exagerada, de ferocidade selvagem e cruel. Centenas deles foram massacrados sem piedade pelos civilizados, e sobretudo pelos semi-civilizados do Peru. (p. 113-4, tradução de Nicolás Niymi Campanário)

27 Sobre a relação entre música, xamanismo e corporalidade ver MATTOS, 2005 (www.oqueseouveentreindice.blogspot.com.br)

${ }^{28}$ Simultaneamente, comprovei, em nível praxeológico e conceitual, o significado central epistêmico atribuído pelos índios Kaxinawa aos processos de transformação visual, que são vivenciados em sua plenitude numa experiência sinestética. Sob a perspectiva dos Kaxinawa, as experiências visuais liminais - que em geral podem ser relacionadas tanto a sonhos, delírios febris, comas e alucinações, quanto a certos modos de contemplação de padrões ornamentais permitem participar da metamorfose continuamente possível de formas e dimensões. Através deste processo de participação, por meio da auto-experiência sensorial-corporal, manifestam-se os princípios mitológico-cosmológicos coletivos (Keifenheim, 2002).
} 

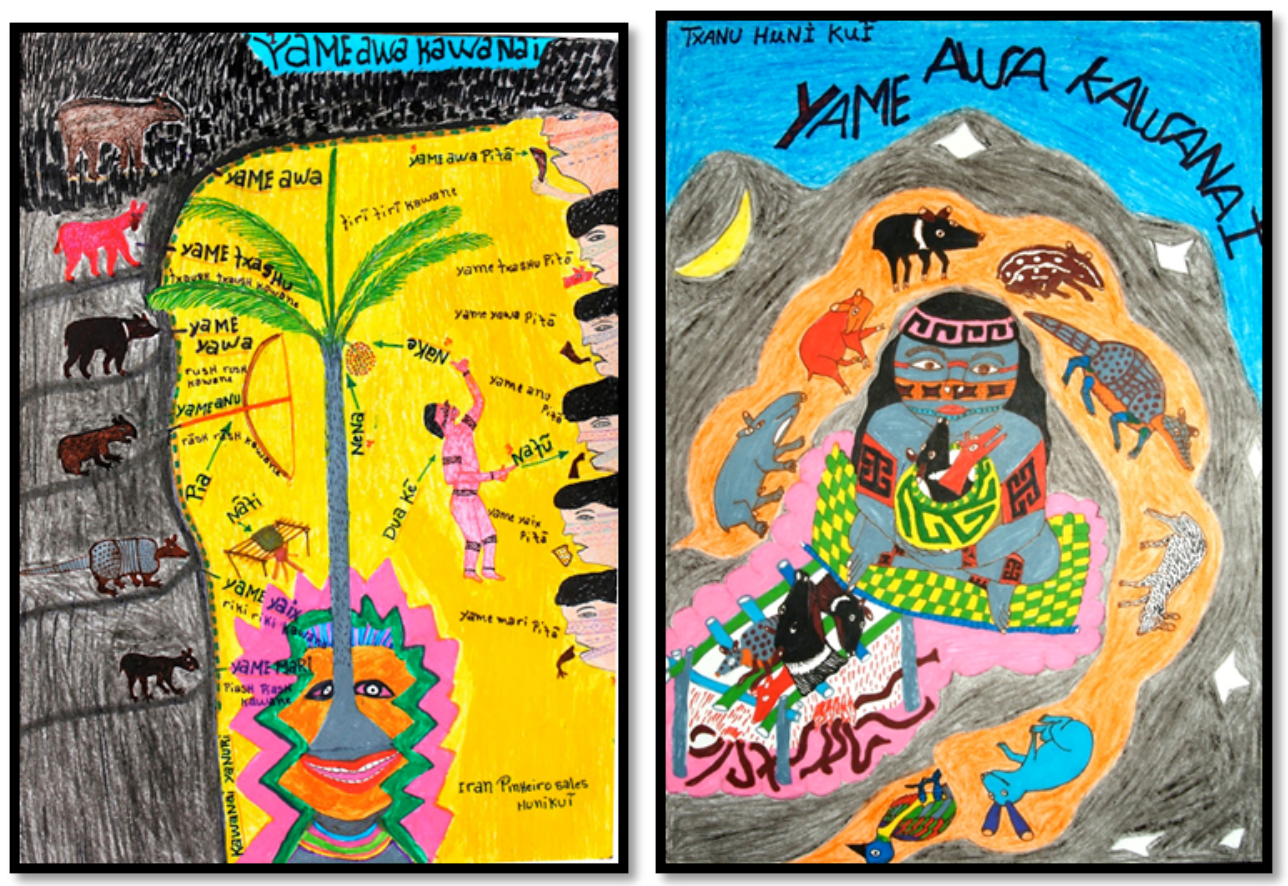

Esse canto se chama Yame awa kawanai, é o dono do espírito da noite. Yame é noite, awa são as antas que passam à noite. Está dizendo que anta vem te pegar, te comer; dentro da miração falando. Então você responde: pia nãti duaken; quer dizer: anta não vai me pegar, me comer, eu que como a anta. $\mathrm{E}$ segue: você come anta, então vem veado... e segue o mesmo diálogo com o veado, o porquinho, tatu, paca, cutia são todos encantados. Você está trocando fala com o espírito, trocando experiência com yuxibu. O espírito é como adversário $^{29}$. Ao mesmo tempo você está curando e mandando diminuir a força.

\section{História do kapetawã}

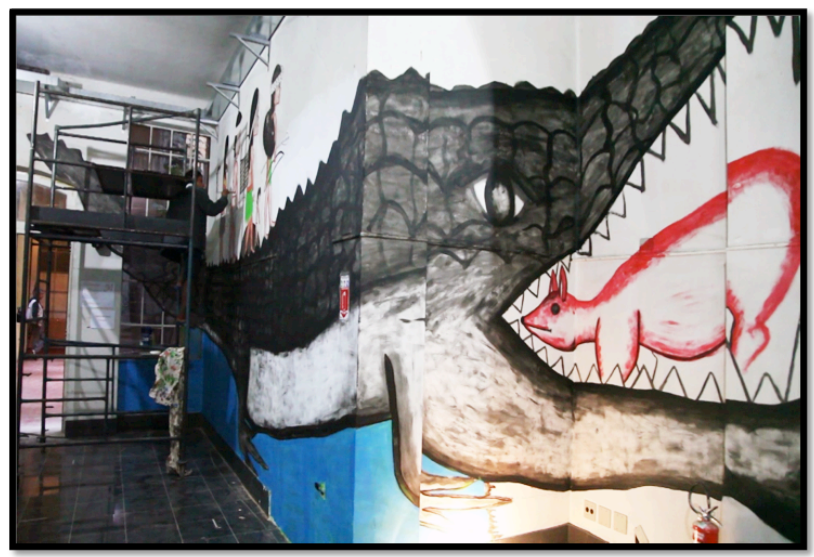

O vídeo $O$ sonho do nixi pae mostra ainda o MAHKU no projeto Feito por brasileiros, em 2014. Fomos convidados pela artista Naziha Mestaoui para compor a obra Yubepã damiwani (Sounds of light), uma instalação com

29 "Bebimos nixi pae. Antes de empezar los cantos, hablamos un poco. La infusión empezó a hacerme efecto y bebí un poco más. No tardé en temblar todo. La tierra tembló. Sopló el viento y los árboles se balancearon... La gente del nixi pae empezó a aparecer. Tenían arcos y flechas y querían disparar contra mí. Yo tuve miedo, pero mi dijeron que sus flechasno me matarían, sólo me emborracharían más...” (Kensinger, 1976: 20). 
pinturas nas paredes do antigo Hospital Matarazzo em São Paulo. Os motivos foram dois: Exeika, a jiboia, e o Kapetawã, o jacaré-ponte. Imagens de Ibã, Bane e Isaka pintando a obra Yubepã damiwani:
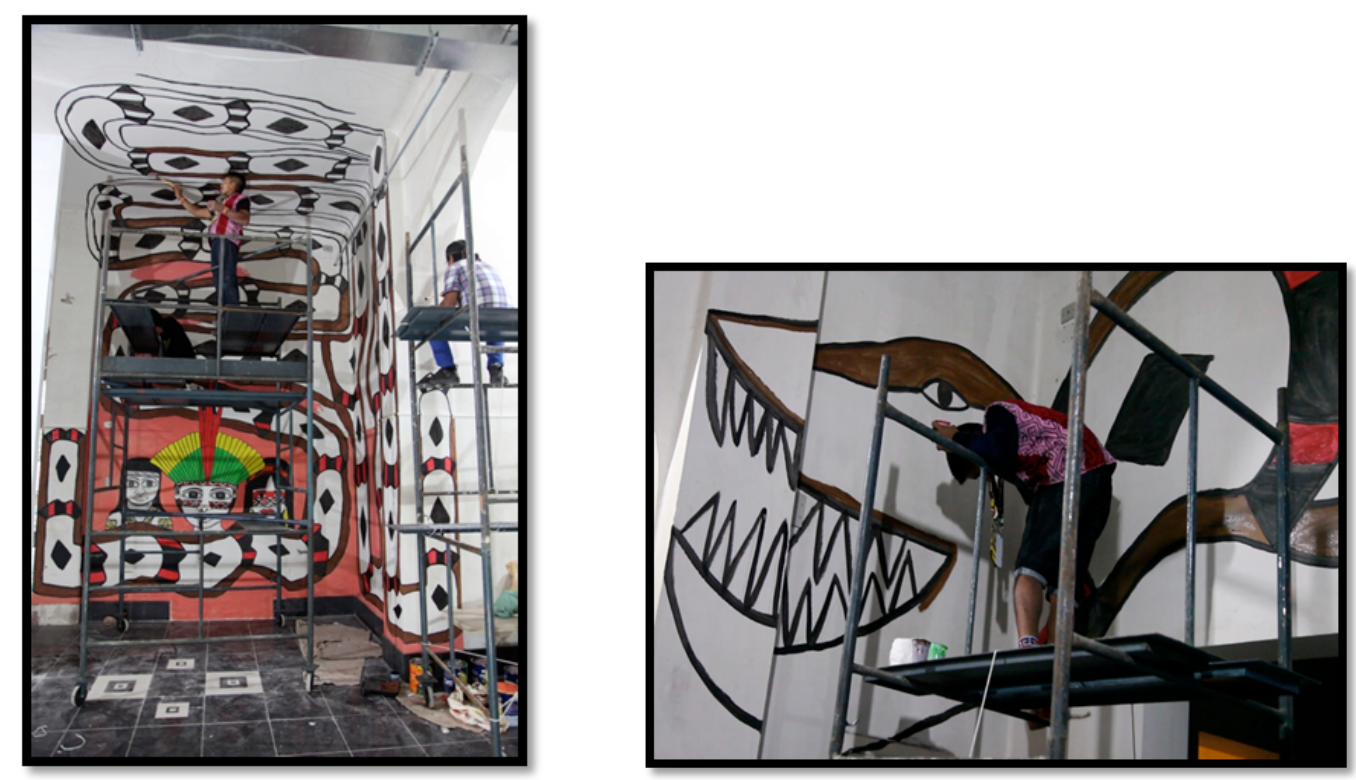

E ainda no Instituto Tomie Ohtake, em 2014, Ibã canta e conta para Bruce a narrativa do kapetawã (jacaré-ponte):

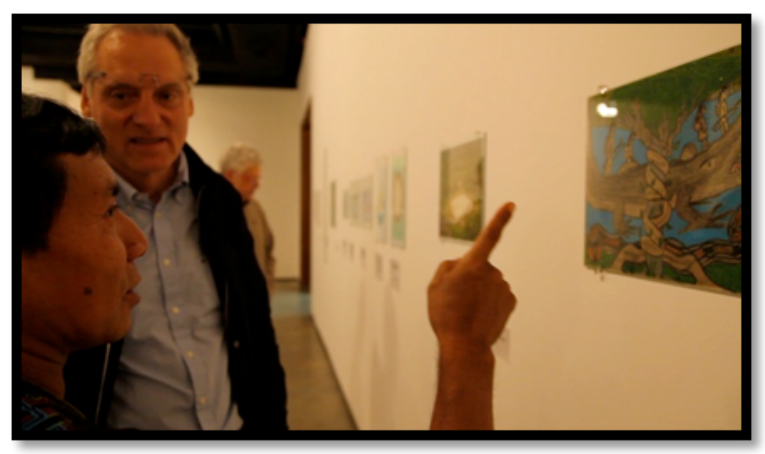

Essa txai Bruce, essa aqui que a gente atravessava, a nossa ponte, pro outro lado, chama Estreito de Bering, na nossa língua chama kapetawã, que tem uma música, uma fala antiga que deu pra nós, na língua do jacaré... (Ibã canta) ...diz que atravessado pro outro lado, um lago bem grande, de um lado da terra ao outro lado da terra, pedindo: oh meus filhos, se quiser atravessar nas minhas costas, eu troco com você, mata caça pra mim: veado, porquinho, mas não mexe jacarezinho pequeno, esse é minha casca; aí os jovens atravessando matavam caça; todo mundo passando, acabando as caças, ficou só jacaré; aí finalmente: rapaz, não tem como nós caçarmos, vamos matar esse jacaré e dar pra esse velho? Tã... (não deixou mais) e a história é essa; essa música que nós ainda temos guardada foi ele que deu... 


\section{Referências}

CAMPOS, Haroldo de. Deus e o diabo no Fausto de Goethe. São Paulo, Perspectiva, 1981.

CARNEIRO DA CUNHA, M. (Org.) Tastevin: fontes sobre índios e seringueiros do Alto Juruá. Museu do índio/Funai, 2009.

CESARINO, Pedro de Niemeyer. De duplos e estereoscópios: paralelismo e personificação nos cantos xamanísticos ameríndios, Mana, 12 (1), 2006.

DELEUZE, G. e GUATTARI, F. Mil platôs, vol. 4, tradução de Suely Rolnik, São Paulo: Ed. 34, 1997.

IBÃ, Isaias Sales. Nixi pae, O espírito da floresta, Rio Branco, CPI/OPIAC, 2006.

. Huni Meka, Os cantos do cipó. IPHAN/CPI, 2007.

KEIFENHEIM, Barbara. Nixi pae como participação sensível no princípio de transformação da criação primordial entre os índios kaxinawa no leste do Peru, In: LABATE, B. C.; ARAUJO, W. S. (orgs.) O Uso Ritual da Ayahuasca. Campinas: Mercado de Letras/São Paulo: Fapesp, 2002.

KENSINGER, Kenneth. El uso del 'Banisteriopsis' entre los cashinahua del Perú. HARNER, Michael. Alucinógenos y chamanismo, Madrid, Punto Ômega,1976.

MATTOS, Amilton Pelegrino de. O que se ouve entre a opy e a escola? Vozes $e$ corpos na ritualidade guarani, Faculdade de Educação, USP, 2005.

ROMANDINI, F.L. Para além do princípio antrópico. Por uma filosofia do Outside. Desterro, Cultura e Barbárie, 2012.

VIVEIROS DE CASTRO, Eduardo. A inconstância da alma selvagem, São Paulo, Cosac \& Naify, 2002.

Perspectival Anthropology and the Method of Controlled Equivocation, Tipití, 2004, 2(1): 3-22.

WAGNER, Roy. A invenção da cultura, tradução de Marcela Coelho de Souza e Alexandre Morales, São Paulo, Cosac e Naify, 2010. 